\title{
Construction of Team Effectiveness Model Based on Paternalistic Leadership Style and Team Member Interaction
}

\author{
Lin Sen ${ }^{1, a}$ Wang Ping ${ }^{2, b, *}$ \\ ${ }^{1}$ School of Economics and Management, Zhejiang Sci-Tech University, Hangzhou310018, China \\ ${ }^{2}$ School of Economics and Management, Zhejiang Sci-Tech University, Hangzhou310018, China \\ ${ }^{a} 737633635 @ q q . c o m,{ }^{b}$ wp190923@163.com
}

\begin{abstract}
In the era of knowledge economy, the teamwork model has become the mainstream of the times, and the team effectiveness has been increasingly concerned by enterprises. Leadership style and team member interaction are the main factors affecting team effectiveness. Based on the paternalistic leadership style and team members' interactions, this paper constructs a new management model of team effectiveness, and studies two types of paternalistic leadership: benevolent leadership and authoritative leadership, and studies two types of team members' interactions: fact-oriented and emotional orientation. This paper studies their respective mechanisms of influence on team effectiveness, and explored the team effectiveness improvement strategies under different team modes, and the transition paths between different team models, and proposed a new suggestion for improving team effectiveness.
\end{abstract}

Keywords: team effectiveness, paternalistic leadership, team member interaction

\section{INTRODUCTION}

In the era of the knowledge economy, independent individual work models are becoming increasingly rare, and replaced by team work methods with greater potential and responsiveness. A good team cooperation model enables each team member to give full play to each other's strengths and promote each other, thereby achieving excellent team effectiveness, maximizing team output, and bringing considerable benefits to individuals and organizations.

The way teams work is different from previous individual work mode. A team is a special social group composed of many complex individuals. Whether it is individual personality differences, conflicts of interest, leadership style characteristics, or changes in the organizational environment, have a continuous and dramatic impact on team effectiveness. Among various influencing factors, the organizational environment is an external influencing factor of team effectiveness, and leadership style and team member interaction are its internal influencing factors. Compared with external factors, internal factors are more controllable factors for the team, so the improvement of team effectiveness should start with internal factors.

Within the team, leadership and members are the most important elements. From the perspective of leadership, leaders can coordinate team relationships, guide the direction of the team, and improve team output. Therefore, leadership style has become one of the important internal factors affecting team effectiveness. Under the Chinese scenario, the most representative leadership style is paternalistic leadership. From the perspective of team members, smooth communication and mutual concern among members, creating a good team atmosphere, can further promote team effectiveness, and the interaction among team members is another key internal factor affecting team effectiveness. Therefore, how to comprehensively consider these two factors, explore their respective and common effects on team effectiveness, build a team effectiveness model, and find a new way to improve team effectiveness has become the focus of current research.

\section{Analysis of key drivers of team effectiveness}

Team effectiveness refers to the extent to which a team completes team goals, meets the needs of members, and maintains its own existence [1], including performance effect, attitude outcome, and behavioral results [2]. The factors that affect team effectiveness are divided into internal factors and external factors. Among them, the internal factors mainly include leadership style and team member interaction.

\subsection{The influence of leadership style on team effectiveness}

Team leadership is an up-down interaction. It promotes cooperation and communication among members by developing a good team interaction environment, which in turn triggers team members to pursue and achieve 
common goals of the team. As one of the two main bodies of the team, different leadership styles of the leader will affect the team's emotional intelligence, team atmosphere, etc., and the team's emotional intelligence will have a huge effect on team effectiveness [3] and will have a profound impact on team effectiveness.

Paternalistic leadership, as a product of traditional Chinese Confucian culture, Legalist ideology and family concepts, is a representative Chinese leadership style. Paternalistic leadership includes three types of benevolent leadership, authoritative leadership and moral leadership [4]. Among them, benevolent and authoritative are the most conflicting leadership styles.

\subsubsection{The impact of benevolent leadership on team effectiveness}

Benevolent leadership refers to the leadership behavior that leaders care for the welfare of subordinates comprehensively and for a long time, and magnanimous to subordinates' behaviors. In the Chinese context, benevolent leadership stimulates employees' sense of obligation to their roles, such as gratitude and loyalty [5], and determines employees' work autonomy. The benevolent leader continuously cares about the welfare of subordinates, improves employee satisfaction, stimulates employee loyalty, trust in the organization, and improves team effectiveness from the perspective of attitude outcome; and, based on the two-factor theory, employee well-being gives employees incentives. The improvement of motivator produces employee satisfaction results, stimulates employees 'enthusiasm for work, and improves labor productivity, that is, improves performance effect of team effectiveness; and because of the harmonious atmosphere within the team, the benevolent leadership negatively affects employees' work shrinking behavior, which can effectively reduce employee turnover [6], promoting team effectiveness from the perspective of behavioral results.

However, the promotion of benevolent leadership to team effectiveness is not absolute. Benevolent leadership cares for the family and life of subordinates. If it is excessive, it will also have a negative effect. For example, some opinionated and privacy-conscious employees think that the care and desire for information of benevolent leaders is a violation of privacy, which will affect employees' work attitudes, which will lead to bad behavior results and affect team effectiveness.

\subsubsection{The impact of benevolent leadership on team effectiveness}

In contrast, the indicative, autocratic and absolute will of authoritative leadership will have the opposite effect with benevolent leadership. The autocratic way of leadership will lead to the lack of parallel communication within the organization, which is not conducive to the interaction and communication of team members [7]. It will negatively affect the team trust and work pleasure of employees. In most cases, it will have a negative effect on employees' work attitude. However, for the performance effect, authoritative leadership can often play a catalytic role, especially for the organization with unclear goals and loose team members. Authoritative leadership can describe the enterprise vision, guide the direction of confused employees, and significantly improve the performance effect. But there are preconditions for authoritative leader to improve performance. Only when employees identify with leaders and have the mentality of trust, or even obedience, otherwise it will lead to management performance reduction, interpersonal harmony damage, or even open conflict.

All in all, both benevolent leadership and authoritative leadership can have an impact on team effectiveness. Benevolent leadership affects team effectiveness mainly by influencing the attitude outcome of employees, improving performance effect, and then affecting team effectiveness; the positive impact of authoritative leadership is mainly reflected in the improvement of performance, which is often a negative impact on work attitude, but both of them have certain limitations on team effectiveness. Comparatively speaking, the positive effect of benevolent leadership on team effectiveness is stronger than that of authoritative leadership.

\subsection{The influence of team member interaction on team effectiveness}

Team interaction is an important form of team activities. It is a kind of cooperative behavior that team members interact and depend on each other in order to achieve team goals [8]. High psychological sharing and low-level intra group conflict caused by high team interaction are conducive to the cultivation of creativity, thus improving team performance and satisfaction [9]. Moreover, each dimension of team interaction process is significantly related to team effectiveness [10]. Therefore, the way team members interact will have an impact on team effectiveness.

Starting from the overall effect of team interaction, the whole process of team interaction shows two overall tendencies: fact-oriented and feeling-oriented [11].

\subsubsection{The impact of fact-oriented team interaction on team effectiveness}

The fact-oriented of team interaction is that in order to achieve team goals, the authenticity and comprehensiveness of information, resources and other useful support provided by the team members as a whole, as well as the independence and objectivity of expressing ideas and opinions [8]. The authenticity and comprehensiveness of the information exchanged by the team, as well as the innovativeness of the ideas, can help 
the team better complete the team tasks and enhance the team's creativity. In addition, social interaction has a greater impact on creativity, and creativity is highly related to team effectiveness, and its role as an intermediary variable significantly affects team effectiveness [9].

Therefore, in the fact-oriented of team interaction, the authenticity and comprehensiveness of information make the task analysis more objective and reasonable; the innovativeness of ideas, helping the organization solve old problems, and developing new business, will significantly promote the performance of the team.

\subsubsection{The impact of feeling-oriented team interaction on team effectiveness}

The feeling-oriented of team interaction refers to the emotional connection of team members with other members during the interaction process, and members maintain attention to the emotions of other members during the interaction process. Team members take care of others, respect others, and respect conflicts of opinions, making members have good relationships, easy exchange of opinions, and improved communication efficiency, which will enhance team creativity and thereby improve team performance; and, team members will encourage each other and maintain emotional connections, which will make Employees work happily and work with high enthusiasm, which promotes a good overall work attitude of the team and further promotes team effectiveness.

The fact-oriented and feeling-oriented of team interaction enables team members to share resources and influence each other to jointly create a harmonious team work atmosphere. The two dimensions of team interaction have a positive effect on the performance, attitude and behavior of team effectiveness.

\section{TEAM EFFECTIVENESS MODEL CONSTRUCTION}

From the above point of view, it can be seen that the two main bodies within the team, leaders and members, each have an effect on team effectiveness, while in the actual team, the leadership style of leaders and different ways of team interaction exist at the same time. What kind of team effectiveness results will be produced when the two interact? This section will build a new management model of team effectiveness, and analyze the different team types combined by different leadership styles and team interaction, and the resulting different team effectiveness.

\subsection{Model establishment}

Taking team interaction (fact-oriented / feeling-oriented) as the horizontal axis and leadership style (benevolent / authoritative) as the vertical axis, the team effectiveness model is established as follows:

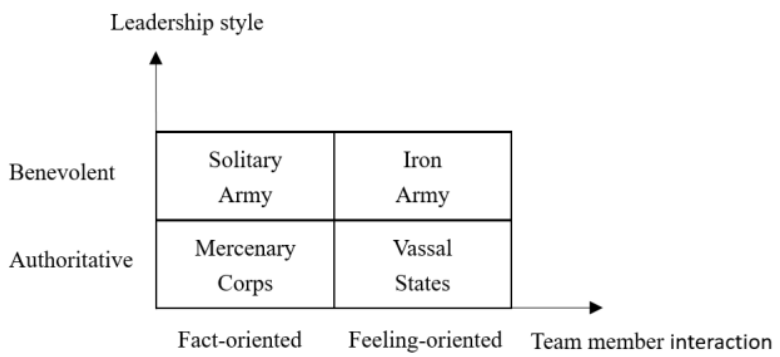

Figure 1 Diagram of team effectiveness model based on leadership style and member interaction

\subsection{Model description}

According to different combinations of team leadership styles and team member interactions, the team types are divided into 4 types:

\subsubsection{Solitary Army: benevolent leadership - fact oriented member interaction}

When the leader adopts a benevolent leadership style, and the members' interactions tend to be fact-oriented, because the leader pays attention to emotional connection, and the members pay attention to the exchange of factual information, and the emotional attention is low, there will be situations where the leader "wishful thinking" to maintain the relationship: leaders expressing concern for the lives of employees, but employees only care about the exchange of information related to the team's goals, and are unwilling to exchange too much personal affairs, which affects the leaders' mood. In the long run, when leaders realize that their previous leadership habits do not adapt to the team, work confidence and enthusiasm will be affected. The weak response of members will negatively affect the effectiveness of leadership.

In addition, the loose management style of benevolent leadership is a time bomb for the fact-oriented employees. The fact-oriented employees pay more attention to the authenticity, integrity and reliability of information, while the benevolent leaders neglect the poor work effect of some employees, which will cause the employees' unfairness. Therefore, in the face of the affectionate care of benevolent leaders, fact-oriented members often make a "disrespect" response, which makes leaders appear to work hard to maintain relationships, and their subordinates are go-it-alone phenomena, so they are named "Solitary Army" teams. It can be seen that the "Solitary Army" team under the combination of benevolent leadership and factoriented interaction mode has a poor team working atmosphere, affected work output and generally low team effectiveness. 


\subsubsection{Iron Army: benevolent leadership - feeling oriented member interaction}

Different from the "Solitary Army", if the team interaction is feeling-oriented and the leadership style is benevolent, the interaction between leaders and employees is frequent, the emotion is well maintained, the communication between superiors and subordinates is smooth, and the relationship is "iron", just like the "Iron Army" in war. Team members usually care about each other and have close emotional ties. When encountering a situation, the leader often says "follow me" instead of "you rush forward" and lead the battle with members. Leaders don't criticize too much for people's underperformance, and members will respect each other and take care of each other's feelings. Therefore, members will also work hard to prevent leaders from worrying. Therefore, it is named "Iron Army" team. This kind of team mode has good working atmosphere, sufficient work motivation, high working efficiency and high team effectiveness.

\subsubsection{Mercenary Corps: authoritative leadership - fact oriented member interaction}

The leader adopts authoritative leadership, and the employees are fact-oriented, and there is often not much emotional connection between them. However, when there is a task, the leader gives instructions. Under the factoriented interactive relationship, employees receive information quickly and can do things as required. Employees are in awe of their superiors and strictly enforce their orders, often with a high degree of work completion. Employees only pay attention to information exchange and do not make too many emotional exchanges. They can also make authoritative leaders feel comfortable, just like the leader of a mercenary corps and soldiers, so they are named "Mercenary" teams. In this team mode, although the team atmosphere is not very easy, it is also harmonious and does not interfere with each other. In addition, the way that leaders absolutely grasp the direction, indicate the road, employees accept information and strictly implement it will make the team achieve higher goals. Therefore, the team effectiveness of this mode is also higher.

\subsubsection{Vassal States: authoritative leadership - feeling oriented member interaction}

The leader adopts an authoritative leadership style, and team member interaction is feeling-oriented. Authoritative leaders tend to be more serious, stay at a high position and keep a sense of distance from their subordinates, while members tend to be emotional oriented in their interactions. Without emotional maintenance, feeling-oriented members will feel uncomfortable, and due to the uncertainty of member relationships, conflicting with their long-term cognition, it is easy to worry and doubt about work tasks.
In addition, feeling-oriented employees have smooth information exchange, frequent communication and close contact with each other, and team members tend to have high autonomy. However, authoritative leaders give orders according to their own will and do not communicate with other members, which will cause suspicion and mistrust of employees, and then disobey them, and even form small groups to oppose the control of authoritative leaders. Just like the vassal states and the emperor, the leader wants to establish authority, but the members are their own camps, have different ideas, are unwilling to obey, and the members' minds are hard to unify. Therefore, they are named as the "Vassal States" team. While team members have their own ideas, they will contradict the character of authoritative leadership. As a result, the team atmosphere is getting worse and worse, the team work is difficult to carry out, the team performance is low, and the team eventually collapses. In this mode, team effectiveness is extremely low.

\section{MODEL APPLICATION}

\subsection{Different teams adopt different ways of improving team effectiveness}

\subsection{1. "Solitary Army" teams should increase their focus on facts}

The emergence of "Solitary Army" teams is mainly due to the fact that leaders pay less attention to information, while team members pay too much attention to facts but lack emotional orientation, and the focus between leaders and members deviates, leading to conflicts. Therefore, one improvement strategy is for leaders to increase their focus on facts. Aiming at the fact that fact-oriented employees are concerned about the authenticity and impartiality of information, a clear reward and punishment mechanism should be established to increase employees 'fairness; appropriately reduce the concern and reduce the insecurities of employees' privacy being snooped; and clear the direction of the team. However, the loose leadership style of benevolent leaders will inevitably lead to the fuzziness of information and the indecision of decision-making. Therefore, it is difficult to change the leadership style for benevolent leaders. Another strategy is that employees improve emotional communication, adapt to the style of benevolent leadership, increase internal contact of the team, break the situation of leadership "solitude", and create a good team atmosphere, which will significantly improve team effectiveness. 


\subsection{2. "Iron Army" teams should expand the scope of "care"}

The "Iron Army" team is the closest of the four types of teams, with a good working atmosphere and a good level of work performance, but as the times progress, the superiority of the "Iron Army" team mode will also be challenged. In the past, it was common for employees to stay in a company for their entire lives. Leaders caring about their employees' life emotions can make employees feel very belonging and make them more loyal. But nowadays, employees rarely stay in one company. In the new era, employees have stronger self-awareness, deeper development concepts, and more emphasis on career planning. This requires that the "care" of benevolent leaders should not be limited to life and emotions, but gradually expand to employee work and development prospects, pay attention to improving employee job satisfaction, give employees suitable work, and give employees professional counseling and vocational training, and truly consider the employee's career development. Expanding the "care" of benevolent leaders and bringing feeling-oriented employees closer to the organization is the development direction of the Iron Army team.

\subsection{3. "Mercenary Corps" team should have new group norm form}

The "Mercenary Corps" team has a serious internal atmosphere, and leader within the organization makes his own decisions. The decision-making efficiency is high, and the team's direction is clear. In traditional enterprises, team efficiency is often very high. However, modern employees pursue democracy and freedom, and autocracy of leaders often causes employees to feel resentment. Therefore, today's authoritative leaders cannot rely on personal authority to regulate employees' behaviour, but also rely on culture and systems to regulate. Through the cultivation of culture and the provisions of the system, employees are consciously observed and obey the will of the leaders. The use of rules to regulate will be more convincing than in the past the form of regulation controlled by individual authority. In addition, in today's changing business society, mercenary teams often fail to keep up with the trend of the times due to the single thinking and rigid team thinking within the team, which is not sustainable in the current society. Therefore, for the team's innovation, learning and development, certain authorization is necessary, which can make the team more flexible and solve the above-mentioned employee autonomy problem to a certain extent. It is an excellent team efficiency improvement strategy for the new era "Mercenary Corps" team.

\subsubsection{The "Vassal States" team increases members' emotional connection}

The "Vassal States" team originates from the conflict between the autocracy of leadership and the high autonomy of feeling-oriented employees, as well as the conflicts between leaders' indifferent communication styles and their subordinates' cherished emotional connection. Therefore, the corresponding improvement strategy is that the leader appropriately increases emotional connections, authorizes appropriately, improves employee autonomy, and meets the emotional needs of team members. At the same time, team members should understand the personality characteristics of the leader, reduce the snooping of leader's information, communicate appropriately, and respect the leaders adequately. This can also change the attitude of the leaders, because generally authoritative leaders "save face", only to be respected first, are willing to contact and exchange more.

\subsection{Leading team effectiveness improvement through team mode conversion}

In the model, "Solitary Army" teams and "Vassal States" teams have lower effectiveness, while "Iron Army" teams and "Mercenary Corps" teams have higher effectiveness. Therefore, a feasible strategy for improving team effectiveness is the mutual conversion of team types, that is, the low-effectiveness team types are transformed into high-effectiveness team types through appropriate changes of leaders and members. The internal structure of a "Mercenary Corps" team has limitations in the ability to adapt to modern society, and the feasibility of converting each team type to this type is poor. Therefore, the best and most feasible way is to transform the low-effectiveness team into an "Iron Army" team with close internal connections and high team output, so as to improve team effectiveness.

\subsection{1. "Solitary Army" $\rightarrow$ "Iron Army"}

The leadership of a "Solitary Army" team is benevolent. The benevolent leadership style is generally opposed to the authoritative style. Therefore, it is often difficult to change from a "Solitary Army" team to a "Mercenary Corps" team. The more feasible path is to move right in the model diagram and turn to the "Iron Army" team. The key to the transformation from "Solitary Army" to "Iron Army" is the fact that the team member interaction has changed from fact-oriented to feeling-oriented. In a "Solitary Army" team, leaders are apt to feel powerless, because the emotional communication of leaders is often not responded. In order to achieve transformation, the leader's first job is to meet the fact-oriented needs of employees and give them true, objective and comprehensive information. And continue to melt the relationship, increase employee interaction, such as more team building, 
Role of Emotional Labor, Beijing: Capital University of Economics and Business, 2018. good relationship and change with employees. From the perspective of employees, correspondingly, they should pay more attention to the feelings of leaders, take care of other people's emotions, and maintain the relationship among all members of the team, not just the superiors. In this way, in order to achieve the transformation from "Solitary Army" to "Iron Army".

\subsection{2. "Vassal States" $\rightarrow$ "Iron Army”}

In a "Vassal States" team, the leader makes decisions alone, and the subordinates often form small groups to confront him, so the leader often feels isolated. In order to improve this situation, the feasible way is that the authoritative leader changes appropriately and increase the contact with employees. Because feeling-oriented subordinates expect mutual respect and concern in essence. If the authoritative leader gets off his high horse and tries to communicate, he will get positive feedback. After strengthening the emotional connection, the authoritative leader should further increase the authorization, and the internal relations of the team will gradually become closer. From the scattered "Vassal States" to the "Iron Army", team effectiveness will be significantly improved.

In addition, because feeling-oriented employees often have high autonomy, it is difficult to simply require them to be obedient and execute command-oriented employees. Therefore, the transition from "Vassal States" to "Mercenary Corps" is less feasible.

\section{REFERENCES}

[1] Ge Shaohu, Study on strategies to improve team effectiveness in organizational management, Northern Economy, issue NO.14, 2013, pp. 60-61.

[2] Cohen S G and Bailey D E, What makes teams work: Group effectiveness research from the shop floor to the executive suite, Journal of Management, vol.23, issue NO.3, 1997, pp. 239-290.

[3] Li Yi, Research on the relationship between team emotional intelligence, leadership behavior and team effectiveness, Kunming: Kunming University Of Science And Technology, 2010.

[4] Tzu-Ting Lin, Bor-Shiuan Cheng, and Zhou Lifang, Review and Prospect of Paternalistic Leadership: Be Thinking Once More, Quarterly Journal of Management, issue NO.4, 2017, pp. 1-32.

[5] Jiing-Lih Farh, Paternalistic leadership in Chinese organizations, Management @ People, issue NO.10, 2009, pp. 55-57.

[6] Wang Chen, The Impact of Benevolent Leadership on the Retreat of Subordinates' Work: The Mediating
[7] Chen Xu, Research on the influence mechanism of team leadership on team effectiveness, Science Research Management, vol. 27, issue NO.4, 2006, pp. 138-141.

[8] Chen Yingxin, The impact of team interaction of major scientific research projects on the quality of teamwork, Guangzhou: South China University of Technology, 2018.

[9] Lin Yuhao and Chen Yingkui, Review and Prospect of Team Effectiveness Research, Management and Administration, issue NO.10, 2019, pp. 54-58.

[10] Wang Haixia, Research on the impact of team interaction process on team effectiveness, Tianjin: Tianjin University of Finance and Economics, 2008.

[11] Chen Guoquan and Zhao Huiqun, Team interaction dual F-oriented theory, scale development and interaction style, Business Management Journal, issue NO.3, 2011, pp. 79-86. 